\title{
The Close Linkage between Nutrition and Environment through Biodiversity and Sustainability: Local Foods, Traditional Recipes, and Sustainable Diets
}

\author{
Alessandra Durazzo \\ CREA Research Centre for Food and Nutrition, Via Ardeatina 546, 00178 Rome, Italy; \\ alessandra.durazzo@crea.gov.it; Tel.: +39-065-149-4430
}

Received: 14 May 2019; Accepted: 18 May 2019; Published: 21 May 2019

check for updates

\begin{abstract}
This special issue, "The Close Linkage between Nutrition and Environment through Biodiversity and Sustainability: Local Foods, Traditional Recipes, and Sustainable Diets" is focused on the close correlation between the potential benefits and "functional role" of a food and the territory, including papers on the characterization of local foods and traditional recipes, on the promotion of traditional dietary patterns and sustainable diets.
\end{abstract}

Keywords: nutritional composition; bioactive components; typical/local foods; environmental and socio-demographic factors; traditional recipes; sustainable diets; traditional dietary patterns; Food Composition Databases

\section{Introduction}

There is a close correlation between the potential benefits and the "functional role" of a food and the territory. Nutrition science should support sustainable ecosystems, ecological resources, and healthy environments. Nutrition and environmental sustainability are strictly linked throughout the food system.

Appropriate farming based land use, protection of animal health and welfare, environmental conservation as linked to climate knowledge, soil quality, and landscaping, lead to the improvement of product quality.

The valorization of the typical/local/traditional products by identifying and evaluating food nutritional quality and safety characteristics represents an important goal for the preservation of local agro-biodiversity. Thus, supporting sustainable ecosystems and productive system. In this context, it is becoming important to address consumers towards a sustainable diet and environment-friendly foods and recipes. The determination of the nutritional composition of composite dishes has a key role for defining daily nutrient intakes at the population level and their association with health effects [1]. Specific databases created to promote and preserve the nutritional characteristics of some national traditional foodstuffs and traditional recipes are needed [2]. Studies on the nutritional profile and bioactive components of typical foods, of a territory, as well as traditional recipes are presented in this special issue.

The evaluation of the influence of agricultural practices, wild species, intra-species biodiversity, and environmental factors as well as the elucidation and clarification of the relationships between the environment, the food quality, and health benefits were discussed throughout this special issue.

As instance Miranda-Granados et al. [3] describes the alternative use as antimicrobial of extracts of Chipilín Leaves (Crotalaria longirostrata Hook. \& Arn), a wild plant that grows in the state of Chiapas (Mexico) and is traditionally used as food. 
Lisciani et al. [4] focused their work on the carbohydrates component of some Italian local landraces of garlic, whereas El Riachy et al. [5] studied the chemical and sensorial characteristics of olive oil produced from the Lebanese olive variety 'Baladi'.

An example of food of animal origin was given by Manzo et al. [6], that investigated the influence of ripening on chemical characteristics of a traditional Italian cheese, Provolone del Monaco.

The interesting review of Pacifico [7] showed how upland potatoes satisfied consumer demand for high quality foods linked to traditional areas of origin, new specialties, and niche products endowed with added nutritional value. It is commonly thought that the environmental synergy of the crop improves the potential beneficial properties of the tuber, giving it a special taste and a renowned quality.

It is worth mentioning the work by Blanco-Salas et al. [8] on classification and cataloguing of wild plants potentially used in human food in the protected area Sierra Grande de Hornachos of Extremadura in Spain, that gives an example of how botany knowledge can effectively promote development, enhancement of territories, and biodiversity preservation, by guiding tourism and consumers towards an haute cuisine, new gastronomy, and environment-friendly recipes.

The overall benefits can be described in terms of increasing the nutritional value of local/traditional foods in the various European countries, ensuring their quality and education of consumers regarding the use of those foods, fitting into a recommended dietary food pattern. The envisaged promotion of traditional products throughout environmentally sustainable techniques further contributes to environmental protection. This strategy should represent a valid tool for promotion of socio-economic development, enhancement of territories, and biodiversity preservation.

In this context, as marked in the work of Garanti and Berberoglu [9], the main challenge of a changing marketplace is to ensure that young generations continue consuming traditional products. Indeed in the area of social sustainability of traditional foods, the authors Garanti and Berberoglu [9] studied the perceptions of post-millennials towards traditional cheese products from a cultural perspective, concluding that loyalty towards traditional food products amongst post-millennials is built based on: -the memories that surrounded the food, -the rituals that preparing and eating a food involved, and -the identity that it builds, therefore allowing people to feel a sense of belonging to their ethnic group.

Mabhaudhi et al. [10], by reviewing the potential of indigenous crops in bringing about such transformative change to South Africa's food system, concluded how indigenous crop, being nutrient dense food and adapted to marginal conditions, is an example of sustainable agriculture and can support the existing food system for local farmers. In the perspective of evaluation of contribution to sustainable diets, livelihood needs, and environmental sustainability of the species throughout the geographical range, Maroyi et al. [11] reviewed the use, cultivation, and management of Schinziophyton rautanenii, a multipurpose plant species in Southern Africa: S. rautanenii offers enormous potential for contributing to the fulfillment of the 2030 Agenda for sustainable development goals adopted by the United Nations General Assembly, resulting in improved food security, household nutrition and health, income, livelihoods, ecological balance, sustainable diets, and food systems.

I would like to acknowledge the efforts of the authors of the publications in this special issue.

Conflicts of Interest: The authors declare no conflict of interest.

\section{References}

1. Durazzo, A.; Lisciani, S.; Camilli, E.; Gabrielli, P.; Marconi, S.; Gambelli, L.; Aguzzi, A.; Lucarini, M.; Maiani, G.; Casale, G.; et al. Nutritional composition and antioxidant properties of traditional Italian dishes. Food Chem. 2017, 218, 70-77. [CrossRef] [PubMed]

2. Marconi, S.; Durazzo, A.; Camilli, E.; Lisciani, S.; Gabrielli, P.; Aguzzi, A.; Gambelli, L.; Lucarini, M.; Marletta, L. Food composition databases: considerations about complex food matrices. Foods 2018, 7, 2. [CrossRef] 
3. Miranda-Granados, J.; Chacón, C.; Ruiz-Lau, N.; Vargas-Díaz, M.E.; Zepeda, L.G.; Alvarez-Gutiérrez, P.; Meza-Gordillo, R.; Lagunas-Rivera, S. Alternative Use of Extracts of Chipilín Leaves (Crotalaria longirostrata Hook. \& Arn) as Antimicrobial. Sustainability 2018, 10, 883.

4. Lisciani, S.; Gambelli, L.; Durazzo, A.; Marconi, S.; Camilli, E.; Rossetti, C.; Gabrielli, P.; Aguzzi, A.; Temperini, O.; Marletta, L. Carbohydrates components of some Italian local landraces: garlic (Allium sativum L.). Sustanability 2017, 9, 1922. [CrossRef]

5. El Riachy, M.; Bou-Mitri, C.; Youssef, A.; Andary, R.; Skaff, W. Chemical and sensorial characteristics of olive oil produced from the Lebanese olive variety 'Baladi'. Sustainability 2018, 10, 4630. [CrossRef]

6. Manzo, N.; Santini, A.; Pizzolongo, F.; Aiello, A.; Marrazzo, A.; Meca, G.; Durazzo, A.; Lucarini, M.; Romano, R. Influence of ripening on chemical characteristics of a traditional Italian cheese: Provolone del Monaco. Sustainability 2019, 11, 2520. [CrossRef]

7. Pacifico, D. Upland Italian Potato Quality-A Perspective. Sustainability 2018, 10, 3939. [CrossRef]

8. Blanco-Salas, J.; Gutiérrez-García, L.; Labrador Moreno, J.; Ruiz-Téllez, T. Wild plants potentially used in human food in the Protected Area "Sierra Grande de Hornachos" of Extremadura (Spain). Sustainability 2019, 11, 456. [CrossRef]

9. Garanti, Z.; Berberoglu, A. Cultural perspective of traditional cheese consumption practices and its sustainability among post-millennial consumers. Sustainability 2018, 10, 3183. [CrossRef]

10. Mabhaudhi, T.; Chibarabada, T.P.; Petrova Chimonyo, V.G.; Murugani, V.G.; Pereira, L.M.; Sobratee, N.; Govender, L.; Slotow, R.; Modi, A.T. Mainstreaming indigenous crops into food systems: A South African perspective. Sustainability 2019, 11, 172. [CrossRef]

11. Maroyi, A. Contribution of Schinziophyton rautanenii to sustainable diets, livelihood needs and environmental sustainability in Southern Africa. Sustainability 2018, 10, 581. [CrossRef]

(C) 2019 by the author. Licensee MDPI, Basel, Switzerland. This article is an open access article distributed under the terms and conditions of the Creative Commons Attribution (CC BY) license (http://creativecommons.org/licenses/by/4.0/). 